\title{
Primary health care centres with asthma clinics: effects on patients' knowledge and asthma control
}

\author{
*Karin Lisspers ${ }^{a}$, Björn Ställberga , Mikael Hasselgrenª, Gunnar Johanssonª, Kurt Svärdsuddª \\ ${ }^{a}$ Department of Public Health and Caring Sciences, Family Medicine and Clinical Epidemiology, Uppsala University, Uppsala, Sweden
}

Originally submitted 24th June 2008; resubmitted 26th November 2008; revised version received 22nd March 2009;

further revision 13th April 2009; accepted 4th May 2009; online 22nd July 2009

\begin{abstract}
Aim: To evaluate outcomes for patients attending primary care centres with and without asthma clinics.

Methods: A cross-sectional survey at 42 primary health care centres randomly selected according to organisation of asthma care, 14 with complete, 14 with incomplete and 14 with no asthma clinic according to national criteria. 1,477 randomly selected patients 15-45 years received two questionnaires. Outcomes were: patients' knowledge of asthma; asthma control; and quality of life.

Results: Patients attending primary health care centres with asthma clinics reported more knowledge of asthma but similar levels of asthma control and quality of life. Patients who reported they had visited the asthma nurse during the last year had more knowledge but similar asthma control and quality of life compared to patients who reported they had not. However, with more time allocated for the nurse, $44 \%$ achieved asthma control compared with $27 \%$ at asthma clinics with less time $(p<0.003)$.

Conclusions: Having an asthma clinic at a primary health care centre improves asthma patients' knowledge of the disease, and better asthma control is achieved if the nurse is allocated more time.

(C) 2010 Primary Care Respiratory Society UK. All rights reserved.

K Lisspers, et al. Prim Care Resp J 2010; 19(1): 37-44.

doi:10.4104/pcrj.2009.00043
\end{abstract}

Keywords primary care, asthma management, clinics, knowledge, outcomes, assessment

The full version of this paper, including Appendix 1,

is available at www.thepcrj.org

\section{Introduction}

Asthma, one of the most common chronic diseases in Sweden, with an estimated prevalence of $8-10 \%,{ }^{1-3}$ is today managed mostly in primary care. ${ }^{4}$ This is a challenge, as asthma is a complex disease in terms of both treatment and management and it generates high costs for society. ${ }^{5}$ Modern asthma treatment emphasises asthma control, ${ }^{6}$ and studies have demonstrated that it is possible for many patients to obtain satisfactory control. ${ }^{7}$ However, there are also some reports of poor control for asthma patients in primary care.8.9 One important reason for this could be that patients are not aware of many aspects of the disease and how to manage them in the best way. To enable improvement in asthma control, guidelines emphasise the importance of education about the disease and its treatment in order to empower patients' sense of control. ${ }^{6}$

Therefore, the organisation of asthma care is important, and asthma clinics are today an integral part of many primary health care centres (PHCCS) in Sweden. ${ }^{10}$ The Swedish Respiratory Group in Primary Care established criteria for asthma clinics in 1998, ${ }^{10,11}$ and these criteria have been used to define asthma clinics in this study. Studies evaluating asthma clinics have demonstrated improvements in some aspects of asthma control, ${ }^{12-14}$ and the need for more good quality trials has been highlighted. ${ }^{15}$ Previous studies on changes in quality of life have not been able to show improvements in patients attending asthma clinics. ${ }^{16}$

This is the first large study in Sweden aiming to evaluate outcomes for adult patients attending PHCCs with and without asthma clinics. Our primary hypothesis was that asthma clinics enable patients to increase their knowledge

\footnotetext{
* Corresponding author: Dr Karin Lisspers, Department of Public Health and Caring Sciences, Family Medicine and Clinical Epidemiology, Science Park, SE-751 85 Uppsala, Sweden. Tel: +46 703524721 Fax: +46 241498502 E-mail: k.lisspers@alfa.telenordia.se
} 
and ability to manage the disease in a better way, thus improving asthma control and quality of life.

\section{Methods \\ Sampling}

In 2000, the organisation of asthma care in primary health care centres (PHCCS) in the Uppsala-Örebro region, central Sweden, was investigated. ${ }^{10}$

Of all 238 PHCCs, 16\% had complete asthma clinics, $37 \%$ had incomplete asthma clinics and $47 \%$ had no asthma clinic as defined by the Swedish Respiratory Group in Primary Care. ${ }^{10,11}$ The criteria for a complete asthma clinic are: a trained nurse; a general practitioner (GP) with responsibility for asthma care; access to a spirometer; investigations and patient education according to guidelines; and a scheduled surgery for the asthma nurse as well as a minimum of 0.5 hours per week per 1000 inhabitants allocated time for the asthma nurse. Asthma clinics lacking one or more of these criteria were regarded as incomplete.

Of the original $238 \mathrm{PHCCs}$, the 28 smallest were excluded from the comparison since they generally lacked asthma clinics. ${ }^{10}$ In addition, four PHCCs without computerised medical records were also excluded and 13 declined to participate. The remaining 193 PHCCs were stratified into groups according to the completeness of their asthma clinic and size. From these strata, a random sample of 42 PHCCs was drawn - 14 with complete, 14 with incomplete, and 14 without asthma clinics.

Each of the 42 PHCCs generated a list of all patients with an asthma diagnosis attending the PHCC during the previous 18 months. From these lists, samples of patients in the age range 15-45 years were drawn - all patients from lists containing 40 or fewer eligible patients, and a random sample of 40 patients from longer lists - thus generating a total of 1,477 patients. The upper age limit was chosen to avoid including patients with chronic obstructive pulmonary disease (COPD).

\section{Data collection}

Two questionnaires were mailed to patients, with two reminders when necessary. In the first questionnaire, returned by $1,136(77 \%)$ patients, information was sought on demographics, asthma medication, symptoms, allergy, emergency consultations, smoking habits, occupation, sick leave, and the patient's knowledge about asthma treatment, ${ }^{17}$ (see Appendix 1, available at www.thepcrj.org). The question about sufficient knowledge was scored: "yes, absolutely", "yes, partially" and "no". In our analyses, having asthma knowledge was defined as "yes absolutely", and "yes partially" (except in Table 6 where we analysed 'sufficient knowledge' as "yes, absolutely").

Four questions concerned the treatment goals of asthma: use of less than three doses of short-acting $\beta_{2}$-agonist during the last week; no night- awakenings (during the last week); no emergency consultations; and no courses of oral steroids (during the last six months). Asthma control in this study was defined as the fulfilment of these four treatment goals.

The second questionnaire, returned by 1,098 (74\%) patients, was the asthma-specific quality of life questionnaire, MiniAQLQ. ${ }^{18}$ This has been validated in patients 17 years or older but has also been used in studies with younger patients (personal communication, Juniper EF). Patients were asked to recall their experiences during the previous two weeks and to respond to each question on a seven-point interval scale, ranging from severe impairment $(=1)$ to no impairment $(=7)$. The mean of the overall score was calculated.

Telephone interviews were offered to 104 non-responders ( $27 \%$ of the non-responding sample), of whom $70(67 \%)$ were willing to be interviewed by telephone. In these interviews an abbreviated form of the disease-oriented questionnaire was used. In addition, some variables such as age and sex were known for $90 \%$ of the 104 non-responders.

\section{Asthma clinics}

In a Swedish setting, an asthma clinic is an integral part of the PHCC with a nurse in charge and a GP responsible for the asthma clinic, but all GPs at the centre manage their own asthma patients. The role of the asthma nurse, who works only part-time at the asthma clinic, is to assist in diagnosing and educating the patient. The GP, who is responsible for the clinic, educates and updates the nurse and the other GPs, assists in interpretation of spirometry and clinical data, and provides advice about therapy if needed. The other GPs are responsible for reviewing their patients' treatment and level of asthma control, sometimes together with the asthma nurse.

The study was approved by the Research Ethics Committee at Uppsala University, Sweden.

\section{Statistical methods}

Data were analysed with the SPSS (version 13.0) and SAS (version 9.1) statistical programme packages. The overall average partial non-response proportion (missing data in returned questionnaires) was $<0.15 \%$ with a specific variable maximum of $2 \%$. Summary statistics such as means, proportions and measures of dispersion were computed with standard parametric methods. Simple differences between groups in continuous data were tested with Student's t-test or analysis of variance, and differences in proportions with the chi-square test.

In the first part of the study we analysed outcomes in patients at PHCCs with and without asthma clinics, and in the second part patients attending asthma clinics at the PHCC during the last year. In the last part outcomes in patients attending asthma clinics in relation to the time allocated for the nurse were analysed. After data were analysed, a power calculation regarding patient-reported knowledge was 
performed. For a difference between PHCCs with and without asthma clinics of $15 \%$, an odds ratio (OR) of 1.53, and an alpha level of 0.05 and $80 \%$ power was obtained with a study population of 800 subjects. The corresponding data for asthma control (difference 2.7\%, OR 1.06, alpha 0.05) would have required many tens of thousands in the study population. The actual power with the present study population was $7 \%$.

Multiple logistic regression was used for analysis of variables influencing asthma control, which provided an odds ratio and a 95\% confidence interval. P-values less than 5\% were considered as indicating statistical significance.

\section{Results}

\section{Characteristics of, and medication use in, the whole study population}

In this study, 399 (35\%) of the patients had access to a complete asthma clinic, 398 (35\%) to an incomplete clinic, and 339 (30\%) of the patients had no asthma clinic at their PHCC (Table 1). At the PHCCs with asthma clinics, 193 patients (50\%) at the complete and 136 (35\%) at the incomplete clinics reported that they had had an appointment with the asthma nurse during the last year. Although the centres without asthma clinics reported they had no asthma nurse, 64 patients (20\%) stated they had an appointment with an asthma nurse during the last year.

At PHCCs with asthma clinics, more patients reported allergies but there were no differences regarding smoking. Scheduled appointments were more common at PHCCs with complete (49\%) and incomplete asthma clinics (46\%) than at PHCCs without asthma clinics $(33 \%)(p<0.001)$. Patients at PHCCs with asthma clinics had medication at a higher treatment step $(p<0.01)$. There was no difference in occupational status between patients at PHCCs with or without asthma clinics.

Table 1. Patient characteristics at primary health care centres with complete, incomplete and no asthma clinics (AC). P for trend calculated with chi square analysis.

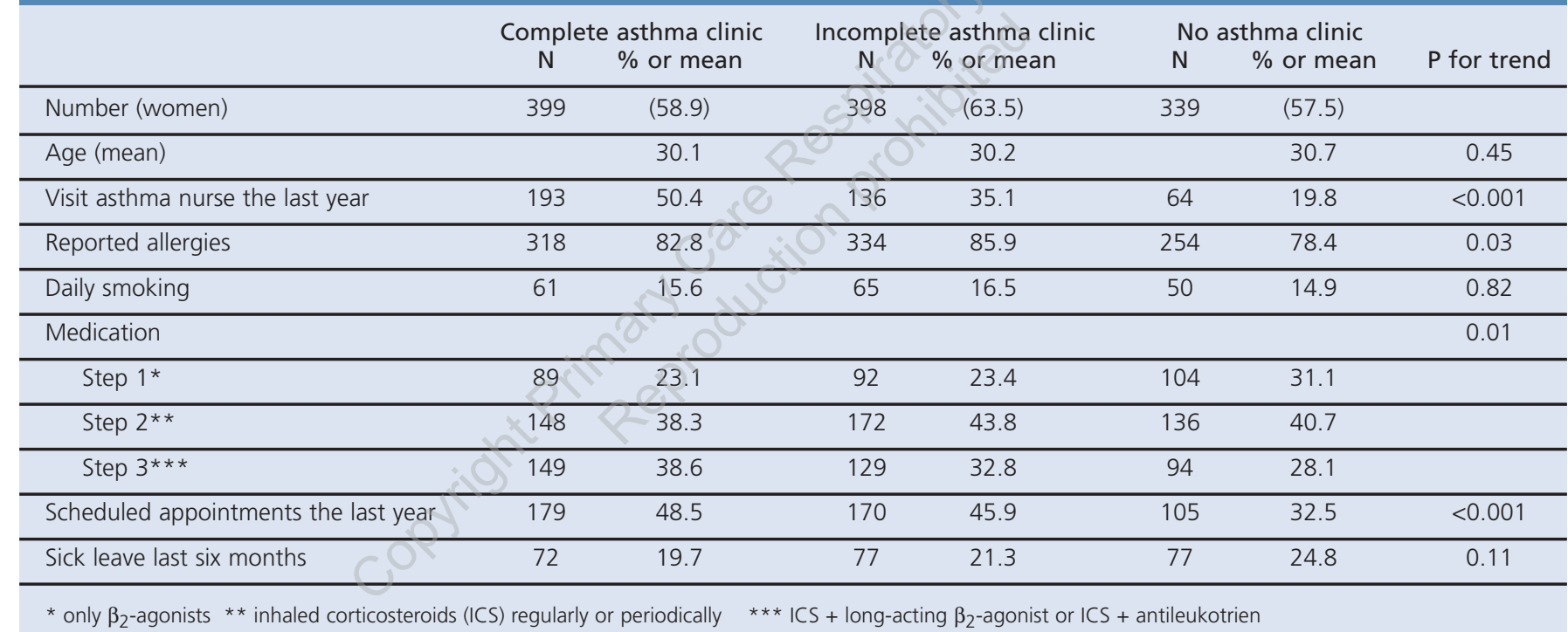

Table 2. Patients' statements about their knowledge of asthma, inhalation techniques, use of peak flow meters and how to adjust medication at variations of the disease. Comparisons between PHCCS with complete, incomplete and no asthma clinics

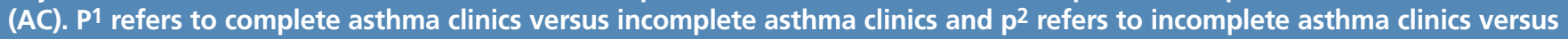
no asthma clinic calculated with logistic regression analysis. $P$ for trend calculated with chi-square analysis.

\begin{tabular}{|c|c|c|c|c|c|c|c|c|c|}
\hline & \multicolumn{3}{|c|}{ Complete asthma clinic } & \multicolumn{3}{|c|}{ Incomplete asthma clinic } & \multicolumn{2}{|c|}{ No asthma clinic } & \multirow[b]{2}{*}{$P$ for trend } \\
\hline & $\mathrm{N}$ & $\%$ & & $\mathrm{~N}$ & $\%$ & & & & \\
\hline Knowledge of asthma & 315 & 81.0 & 0.010 & 289 & 73.2 & 0.01 & 217 & 64.6 & $<0.001$ \\
\hline Education about inhalation techniques & 363 & 93.3 & 0.44 & 350 & 91.9 & 0.04 & 287 & 87.2 & 0.01 \\
\hline Peak flow measurements & 131 & 33.2 & 0.03 & 102 & 26.1 & 0.15 & 72 & 21.5 & 0.002 \\
\hline Adjustment of medication at infections & 236 & 60.4 & 0.04 & 210 & 53.2 & 0.04 & 151 & 45.3 & $<0.001$ \\
\hline Adjustment of medication at more symptoms & 293 & 75.1 & 0.92 & 298 & 75.4 & 0.003 & 220 & 65.5 & 0.003 \\
\hline Adjustment of medication according to peak flow & 210 & 68.9 & 0.11 & 184 & 62.6 & 0.03 & 107 & 53.0 & 0.001 \\
\hline
\end{tabular}




\section{Knowledge and education in the whole study population}

Sufficient knowledge of the disease was reported more frequently by patients at PHCCs with complete $(81 \%)$ than by patients at incomplete asthma clinics (73\%) and with no asthma clinics $(65 \%)(p<0.001)$ (Table 2). Patients at PHCCs with asthma clinics reported they had received education about inhaler techniques and performed peak flow measurements to a higher extent. They were also more aware of how to adjust their own medication at variations of asthma attributable to worsening or infection.

\section{Asthma control, quality of life and knowledge in the whole study population}

There were no significant differences in asthma control or in the various components defining asthma control and quality of life between patients at PHCCs with and without asthma clinics (Table 3). However, the odds for obtaining asthma control for patients stating they had knowledge about the disease was 1.5 (95\% Cl 1.1-2.0), adjusted for age, sex and PHCCs with and without asthma clinics. The relationship between knowledge and the number of achieved treatment goals is illustrated in Figure $1(p<0.001)$.

\section{Criteria for asthma clinics in relation to knowledge} and asthma control

Patients were more knowledgeable about their disease when their asthma clinic had a GP responsible for asthma care ( $p=$ $0.02)$, scheduled office hours for the asthma nurse $(p=0.05)$, offered education according to guidelines $(p=0.01)$, and had more time $(p=0.01)$. There was no difference in asthma control with respect to the various criteria for asthma clinics.

\section{Evaluation of patients who had attended the asthma clinic during the last year}

One third of all patients, 393 (35\%), reported that they had had an appointment with the asthma nurse during the last year. Sixty-four patients attending PHCCs without asthma clinics are excluded, leaving 329 patients. Of these, 62\%

Table 3. Asthma control and quality of life at the PHCCs with complete, incomplete and no asthma clinics. Asthma control is defined as use of short-acting $\beta_{2}$-agonists less than three doses per week, no night awakenings, emergency visits or courses of oral steroids. Quality of life is presented as the mean of the total Mini-AQLQ score. P-values calculated with chi-square and analysis of variance.

\begin{tabular}{|c|c|c|c|c|c|c|c|}
\hline & \multicolumn{2}{|c|}{ Complete asthma clinic } & \multicolumn{2}{|c|}{ Incomplete asthma clini } & \multicolumn{2}{|c|}{ No asthma clinic } & \multirow[b]{2}{*}{$P$ for trend } \\
\hline & & o or mean & & or mean & $\mathrm{N}$ & $\%$ or mean & \\
\hline Short-acting $\beta_{2}$-agonists* & 187 & 48.3 & 184 & 46.5 & 153 & 45.7 & 0.47 \\
\hline Night awakenings** & 102 & 26.6 & 113 & 29.2 & 88 & 26.7 & 0.94 \\
\hline Emergency visits*** & 93 & 23.7 & 96 & 24.4 & 86 & 25.6 & 0.56 \\
\hline Courses of oral corticosteroids $* * *$ & 48 & 12.4 & 60 & 15.3 & 51 & 15.3 & 0.26 \\
\hline Asthma control & 140 & 36.2 & 132 & 33.9 & 111 & 33.5 & 0.45 \\
\hline Quality of life & 374 & 5.48 & 388 & 5.54 & 336 & 5.56 & 0.37 \\
\hline
\end{tabular}

Figure 1. Relationship between patient-reported knowledge (in percent of the total number of patients in the study population) of asthma and achievement of treatment goals $0-4$. Knowledge = yes, absolutely and yes, partially. Treatment goals are defined as: use of less than three doses of short-acting $\beta_{2}$-agonist per week, no night-awakenings, no emergency consultations and no use of oral steroids. P-value calculated with chi-square analysis.

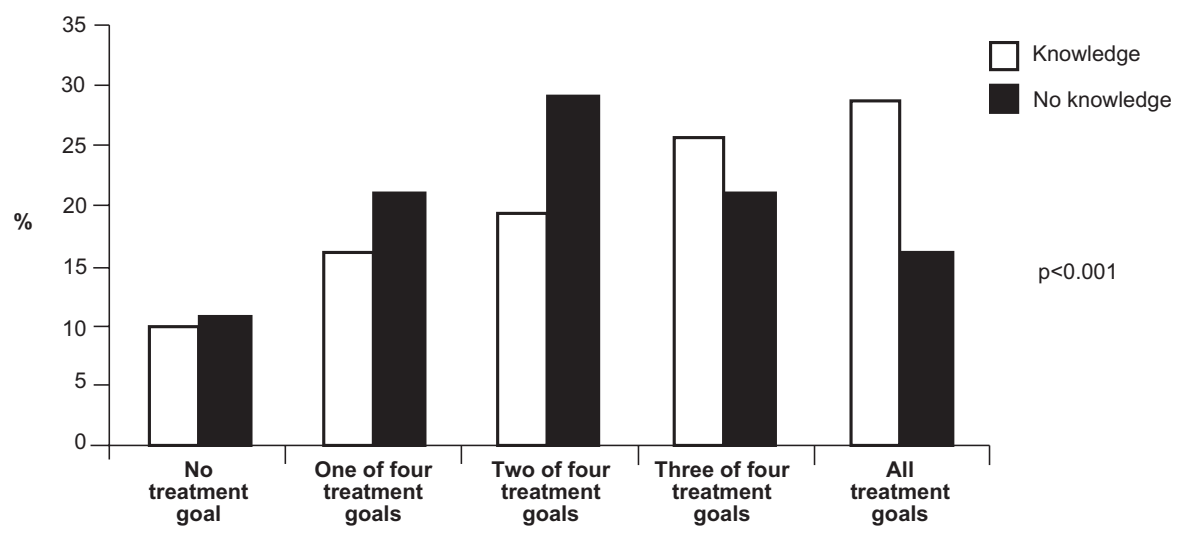


Table 4. Characteristics of patients who reported they had or not had attended the asthma clinic during the last year. Patients at PHCCs without asthma clinics who reported they had visited the asthma clinic are excluded. Patient reported use of peak flow measurements, education about medication and knowledge of how to adjust medication and about asthma. Knowledge of asthma = yes, absolutely and yes, partially. P values calculated with chi-square analysis.

\begin{tabular}{|c|c|c|c|c|c|}
\hline & \multicolumn{2}{|c|}{$\begin{array}{c}\text { Visit to asthma nurse last year } \\
\mathrm{N}\end{array}$} & \multicolumn{2}{|c|}{ No visit to asthma nurse last year } & $P$ for trend \\
\hline Number ( $\%$ female) & 329 & $31.9(61.7)$ & 701 & $68.1(61.1)$ & \\
\hline Daily smoking & 50 & 15.3 & 111 & 15.9 & 0.80 \\
\hline Years with asthma & & & & & $<0.001$ \\
\hline $1-5$ years & 107 & 32.7 & 174 & 25.2 & \\
\hline$>5$ years & 185 & 56.6 & 484 & 70.0 & \\
\hline Medication & & & & s & $<0.001$ \\
\hline Step 1* & 58 & 17.7 & 197 & 28.6 & \\
\hline Peak flow measurements & 133 & 40.8 & 148 & 21.2 & $<0.001$ \\
\hline Education about medication & 316 & 97.2 & 600 & 88.4 & $<0.001$ \\
\hline Adjustment of medication & 274 & 84.0 & 510 & 73.0 & $<0.001$ \\
\hline Knowledge of asthma & 262 & 80.6 & 493 & 70.6 & 0.001 \\
\hline
\end{tabular}

were female, $15 \%$ smokers, and $83 \%$ had allergies with similar figures for those who had not had an appointment (Table 4). Patients who attended the asthma clinic had a shorter history of asthma, medication at a higher step and were more knowledgeable about asthma and adjustment of their medication. They more often reported emergency visits, but had similar asthma control and quality of life to patients who had not attended the asthma clinic (Table 5).

\section{Comparison of patients who attended an asthma clinic with respect to allocated time for the asthma nurse}

Table 6 shows data on patients who had attended the asthma clinic during the last year. Comparisons between patients at asthma clinics with $\geq 1$ hour/1000 inhabitants/week for appointments, and those with less time for appointments, are displayed. There was no difference in smoking or medication, but patients expressed more sufficient knowledge about asthma - $39 \%$ as compared to $27 \%$. Patients at asthma clinics with more time had better asthma control - $44 \%$ as compared to $27 \%$. The means of the total quality of life scores were similar in these two groups.

\section{Effects of non-response}

There were no differences between responders and nonresponders regarding age, sex, duration of asthma, pollen allergy and use of rescue medication.

\section{Discussion}

This is the first large survey in Sweden studying the outcomes for adult asthma patients attending PHCCs with and without asthma clinics. Patients at PHCCs with asthma clinics had medication at a higher step and reported more knowledge about the disease and about how to adjust their medication, but there was no difference in asthma control and quality of life. Patients who had attended the asthma clinic during the last year had a shorter history of asthma, medication at a higher treatment step, better knowledge of the disease, but more emergency visits. When studying asthma clinics with more time allocated for the nurse, more patients reported sufficient knowledge and asthma control. There was a strong relationship between knowledge and asthma control in the whole study group.

In the first part of the analysis, we studied and compared patients with asthma at PHCCs with complete or incomplete asthma clinics and without asthma clinics. It should be emphasised that fewer than half of the patients had an appointment with the asthma nurse during the last year. Despite this fact, patients at PHCCs with asthma clinics stated that they had more knowledge about the disease irrespective of whether or not they had attended the clinic during the last year. If patients had had an earlier attendance, that might explain their better knowledge. Another explanation could be 
Table 5. Asthma control and quality of life in patients who reported they had and had not attended the asthma clinic during the last year. Patients at PHCCs without asthma clinics who reported they had visited the asthma clinic are excluded. Asthma control is defined as use of short-acting $\beta_{2}$-agonists less than three doses per week, no night awakenings, emergency visits or courses of oral steroids. Quality of life is presented as the mean of the total MiniAQLQ score. P-values calculated with chi-square analysis and analysis of variance.

\begin{tabular}{|c|c|c|c|c|c|}
\hline & \multirow{2}{*}{\multicolumn{2}{|c|}{$\begin{array}{c}\text { Visit to asthma nurse last year } \\
\mathrm{N} \quad \% \text { or mean }\end{array}$}} & \multicolumn{2}{|c|}{ No visit to asthma nurse last year } & \multirow[b]{2}{*}{$P$ for trend } \\
\hline & & & $\mathrm{N}$ & $\%$ or mean & \\
\hline Short-acting $\beta_{2}$-agonists* & 156 & 47.7 & 317 & 45.8 & 0.57 \\
\hline Night awakenings** & 89 & 27.6 & 176 & 25.8 & 0.55 \\
\hline Emergency visits*** & 102 & 31.2 & 137 & 19.7 & $<0.001$ \\
\hline Courses of oral corticosteroids*** & 49 & 15.2 & 92 & 13.3 & 0.41 \\
\hline Asthma control & 106 & 32.5 & 254 & 37.1 & 0.15 \\
\hline Quality of life & 316 & 5.47 & 677 & 5.60 & 0.09 \\
\hline
\end{tabular}

Table 6. Comparison of patients who had attended the asthma clinic during the last year. The time allocated for the nurse is expressed as hours per week/1000 inhabitants in the catchment area of the primary health care centre. Sufficient knowledge = yes, absolutely. P-values calculated with chi-square analysis.

\begin{tabular}{|c|c|c|c|c|}
\hline & $\begin{array}{l}\text { One hour or more } \\
\mathrm{N}\end{array}$ & & $\begin{array}{l}\text { one hour } \\
\%\end{array}$ & $P$ \\
\hline Patients (\% female) & $104 \quad 67.3$ & 225 & 59.1 & \\
\hline Allergies & 9290.2 & 177 & 80.5 & 0.03 \\
\hline Daily smoking & $14 \quad 13.6$ & 36 & 16.1 & 0.55 \\
\hline Step 1* & $1 8 \longdiv { 1 7 . 5 }$ & 40 & 17.9 & \\
\hline Step $2 * *$ & 35.9 & 98 & 43.8 & \\
\hline Step $3^{* * *}$ & 48 & 86 & 38.4 & \\
\hline Change medication at infections & 72.8 & 129 & 57.8 & 0.009 \\
\hline Asthma control**** & 43.7 & 61 & 27.4 & 0.003 \\
\hline
\end{tabular}

that doctors and nurses at PHCCs with asthma clinics have more interest in, and knowledge about, asthma - which could result in improved education and more adequate management of patients. Patients at PHCCs with complete asthma clinics were more knowledgeable than patients at PHCCs with incomplete asthma clinics, which implies that achieving all the criteria for an asthma clinic increases the quality of care. However, there were no differences in asthma control and quality of life between patients at the different types of PHCCs. There were no important differences with respect to socio-economic profiles of the patients between PHCCs with and without asthma clinics.

When evaluating patients who reported they had visited the asthma clinic during the last year, they had medication at a higher treatment step and were better informed about their disease and how to adjust medication according to variations in asthma severity. Nevertheless, they had more emergency visits and no better asthma control than patients who had not attended an asthma clinic. One reason could be that patients with more severe and recently diagnosed asthma are referred 
from the GPs at the PHCC to the asthma clinic, since the asthma nurse has more time for education and follow up. This might result in a selection of more severe and not yet controlled asthma patients attending the asthma clinic. Probably as a consequence of more frequent appointments, these patients gain better knowledge of the disease and of how to manage their medication. PHCCs with well functioning asthma clinics are also able to take care of more severe patients rather than having to refer them to the hospital. Most PHCCs have limited time allocated for the asthma clinic, and therefore patients with milder disease are less often referred to the asthma clinic.

When studying outcomes in relation to the allocated time for the asthma nurse, we chose to report the results at the cutoff level of $\geq 1$ hour/1,000 inhabitants/week. From our clinical experience any less time would be insufficient to achieve good quality of care (which was also verified in this study). Patients who had attended asthma clinics with more time reported more knowledge and asthma control. More time increases the possibilities for each patient to receive time for individual needs, which may enable patients to become more aware of the signs and symptoms of the disease..$^{19-23}$ It also enables the nurse and the patient to create a self-management plan, including adjustment of medication in different situations, which may result in more adequate treatment and enhanced asthma control. ${ }^{24-26}$ In Sweden, time allocation for the asthma nurse is a problem in most cases, ${ }^{10}$ which undoubtedly influences the quality of the work performed at the clinic.

There was a positive correlation between some of the criteria for asthma clinics and knowledge, but not for asthma control. On the other hand patients reporting sufficient knowledge, regardless of the type of PHCC, more often had controlled asthma. Supplying good quality education for patients to achieve sufficient knowledge of the disease is one of the cornerstones of the work of an asthma clinic. It is of the utmost importance that the content of education and communication skills employed are of the highest quality and that the time to deliver the education is sufficient. ${ }^{26-28}$

National guidelines in Sweden ${ }^{29}$ recommend asthma clinics in primary care, but few studies have presented positive outcomes. One Swedish study evaluating patients before and after intervention of an asthma nurse demonstrated improvements in asthma control, ${ }^{30}$ but there are few well-designed randomised controlled trials evaluating asthma clinics. In a Cochrane analysis from 2002,31 only one study satisfied the criteria for inclusion:13 this study showed fewer night awakenings and improvement in the use of peak flow meters. ${ }^{13}$ In two more recent randomised controlled trials, one demonstrated fewer emergency visits in the group that had appointments with an asthma nurse, ${ }^{12}$ whilst another did not show a higher quality of life in the patients attending the asthma clinic. ${ }^{16}$

\section{Discussion summary}

a) Difficulties: Logistical problems with so many centres involved in the study and randomisation of patients was performed at the primary health care centres.

b) Alternative methodology: Patient interviews instead of mailed questionnaires.

c) New questions: Would a trial with randomised PHCCs answer the question of possible benefits of asthma clinics?

d) Lessons: Asthma clinics improve patients' knowledge. If the asthma clinic is allocated more time, there is an increased likelihood that more patients will achieve asthma control.

One problem with evaluating asthma clinics is how to create well-designed studies that are randomised with a control-group in "real life". The organisation of primary care and asthma clinics differs between countries. Asthma clinics in Sweden are organised depending on the interest of the PHCC, and there are no economic benefits for the clinic.

The strength of this study is that it included many patients and studied outcomes for patients at PHCCs with and without asthma clinics. It also compared outcomes in patients attending and not attending the asthma clinic during the last year. The fact that the measurement was restricted to only the last year may of course be a limitation: a longer period might have given different results. The organisation of each asthma clinic is known and could be related to the outcomes.

Possible weaknesses include this being a cross-sectional study with questionnaires but no patient examination or use of objective measurements such as lung function. The content of the work of the nurse varies and is not known for individual clinics. The impact of these differences at clinics could not be accounted for when evaluating the results of the study. Twenty percent of the patients at PHCCs without asthma clinics reported that they had visited an asthma nurse during the last year, which of course could question the validity of this particular question. Explanations could be that the patients had changed PHCC, that the asthma clinic had closed, or that the patients had misunderstood the question. Due to this uncertainty we chose to exclude these patients from this analysis.

In conclusion, this study has demonstrated that patients attending PHCCs with asthma clinics are more knowledgeable about their asthma. Patients who had attended the asthma clinic during the last year had similar asthma control and quality of life to patients who had not. With more time for the asthma clinic, more patients achieved asthma control. Asthma 
is a variable disease with many triggering factors, which requires good knowledge on the part of the patients to achieve and maintain asthma control. This underlines the importance of good quality education and recognition of the special needs of the patient to empower them to gain control of the disease. If this is achievable, it is highly likely that patients will maintain a satisfactory quality of life while living with a chronic disease such as asthma. A future study should include a randomised trial in a real life setting with different types of asthma clinics.

\section{Acknowledgements}

The study was supported by grants from the county councils of the Uppsala-Örebro Health Care Region, The Centre for Clinical Research, Dalarna, The Swedish Heart and Lung Foundation, The Swedish Asthma and Allergy Association, The Swedish Heart and Lung Association and Uppsala University. We acknowledge all participating centres and the whole AIM-study group. We would also like to thank Jerzy Leppert, MD, PhD, the Centre for Clinical Research in Västerås, for providing resources for data management.

\section{Conflict of interest declarations}

Karin Lisspers has been paid for lectures and for consulting from AstraZeneca, GlaxoSmithKline and MSD.

Björn Ställberg has been paid for lectures and for consulting from AstraZeneca, GlaxoSmithKline, MSD and Schering Plough.

Mikael Hasselgren has no conflicts of interest.

Gunnar Johansson has received fees for consulting or for speaking at symposia arranged by AstraZeneca, GlaxoSmithKline, MSD and Schering Plough.

Kurt Svärdsudd has no conflicts of interest.

\section{References}

1. Bjerg A, Hedman L, Perzanowski MS, Platts-Mills T, Lundback B, Ronmark E. Family history of asthma and atopy: in-depth analyses of the impact on asthma and wheeze in 7- to 8-year-old children. Pediatrics 2007;120(4):741-8. http://dx.doi.org/10.1542/peds.2006-3742

2. Hasselgren M, Arne M, Lindahl A, Janson S, Lundback B. Estimated prevalences of respiratory symptoms, asthma and chronic obstructive pulmonary disease related to detection rate in primary health care. Scand J Prim Health Care 2001;19(1):54-7. http://dx.doi.org/10.1080/028134301300034701

3. Lundback B. Epidemiology of rhinitis and asthma. Clin Exp Allergy 1998;28(2):3-10

4. Statements of accounts for diagnoses at doctors'visits in 2004 at the primary health care centre in Tierp [cited; Available from: www.pubcare.uu.se/ epidemiologi/diagnosvc/dx2004.htm

5. Jansson SA, Ronmark E, Forsberg B, Lofgren C, Lindberg A, Lundback B. The economic consequences of asthma among adults in Sweden. Respir Med 2007;101(11):2263-70. http://dx.doi.org/10.1016/j.rmed.2007.06.029

6. Global Strategy for Asthma Management and Prevention, Global Initiative for Asthma (GINA) 2007.

7. Bateman ED, Boushey HA, Bousquet J, et al. Can guideline-defined asthma control be achieved? The Gaining Optimal Asthma ControL study. Am J Respir Crit Care Med 2004;170(8):836-44.

8. Rabe KF, Vermeire PA, Soriano JB, Maier WC. Clinical management of asthma in 1999: the Asthma Insights and Reality in Europe (AIRE) study. Eur Respir J 2000;16(5):802-07.

9. Stallberg B, Nystrom Kronander U, Olsson P, Gottberg L, Ronmark E, Lundback B. Living with asthma in Sweden--the ALMA study. Respir Med 2003;97(7):83543. http://dx.doi.org/10.1016/S0954-6111(03)00040-4

10. Lisspers K, Stallberg B, Hasselgren M, Johansson G, Svardsudd K. Organisation of asthma care in primary health care in Mid-Sweden. Prim Care Resp J
2005;14(3):147-53. http://dx.doi.org/10.1016/j.pcrj.2005.03.003

11. Tilling $B$, Johansson $G$, Ställberg $B$. Astmamottagning i primärvård - dags att fastslå kriterier. Allmän Medicin 1998;19:141-2.

12. Griffiths $C$, Foster $G$, Barnes $N$, et al. Specialist nurse intervention to reduce unscheduled asthma care in a deprived multiethnic area: the east London randomised controlled trial for high risk asthma (ELECTRA). BMJ 2004;328(7432):144. http://dx.doi.org/10.1136/bmj.37950.784444.EE

13. Heard AR, Richards IJ, Alpers JH, Pilotto LS, Smith BJ, Black JA. Randomised controlled trial of general practice based asthma clinics. Med J Aust 199;171(2):68-71.

14. Lindberg M, Ahlner J, Ekstrom T, Jonsson D, Moller M. Asthma nurse practice improves outcomes and reduces costs in primary health care. Scand J Caring Sci. 2002;16(1):73-8. http://dx.doi.org/10.1046/j.1471-6712.2002.00054.x

15. Fay JK, Jones A, Ram FS. Primary care based clinics for asthma. Cochrane Database Syst Rev. 2002(1):CD003533.

16. Pilotto LS, Smith BJ, Heard AR, McElroy HJ, Weekley J, Bennett P. Trial of nurserun asthma clinics based in general practice versus usual medical care. Respirology 2004;9(3):356-62. http://dx.doi.org/10.1111/j.14401843.2004.00589.x

17. Hasselgren M, Gustafsson D, Stallberg B, Lisspers K, Johansson G. Management, asthma control and quality of life in Swedish adolescents with asthma. Acta Paediatr 2005;94(6):682-8. http://dx.doi.org/10.1080/ 08035250510025851

18. Juniper EF, Guyatt GH, Cox FM, Ferrie PJ, King DR. Development and validation of the Mini Asthma Quality of Life Questionnaire. Eur Respir J 1999;14(1):32-8.

19. Partridge MR. The asthma consultation: what is important? Curr Med Res Opin 2005;21 Suppl 4:S11-17. http://dx.doi.org/10.1185/030079905X61749

20. Partridge MR, van der Molen T, Myrseth SE, Busse WW. Attitudes and actions of asthma patients on regular maintenance therapy: the INSPIRE study. BMC Pulm Med 2006;6:13. http://dx.doi.org/10.1186/1471-2466-6-13

21. Horne R, Price D, Cleland J, et al. Can asthma control be improved by understanding the patient's perspective? BMC Pulm Med 2007;7:8. http://dx.doi.org/10.1186/1471-2466-7-8

22. Haughney J, Barnes G, Partridge M, Cleland J. The Living \& Breathing Study: a study of patients' views of asthma and its treatment. Prim Care Resp J 2004;13(1):28-35. http://dx.doi.org/10.1016/j.pcrj.2003.11.007

23. Lindberg M, Ekstrom T, Moller M, Ahlner J. Asthma care and factors affecting medication compliance: the patient's point of view. Int J Qual Health Care 2001;13(5):375-83. http://dx.doi.org/10.1093/intqhd13.5.375

24. Gibson PG, Powell H. Written action plans for asthma: an evidence-based review of the key components. Thorax 2004;59(2):94-9. http://dx.doi.org/ 10.1136/thorax.2003.011858

25. Jones MA. Asthma self-management patient education. Respir Care 2008;53(6):778-86.

26. Gibson PG, Powell H, Coughlan J, et al. Self-management education and regular practitioner review for adults with asthma. Cochrane Database Syst Rev. 2003(1):CD001117.

27. Moffat M, Cleland J, van der Molen T, Price D. Poor communication may impair optimal asthma care: a qualitative study. Fam Pract 2007;24(1):65-70. http://dx.doi.org/10.1093/fampra/cml062

28. Partridge MR. Living with a variable disease. Pulm Pharmacol Ther 2002;15(6):491-6. http://dx.doi.org/10.1006/pupt.2002.0399

29. Socialstyrelsens riktlinjer för förebyggande, diagnostik, behandling och rehabilitering av astma och KOL. 2004 [cited; Available from: www.sos.se

30. Lindberg M, Ahlner J, Moller M, Ekstrom T. Asthma nurse practice--a resourceeffective approach in asthma management. Respir Med 1999;93(8):584-8. http://dx.doi.org/10.1016/S0954-6111(99)90159-2

31. Gibson PG, Powell H, Coughlan J, et al. Limited (information only) patient education programs for adults with asthma. Cochrane Database Syst Rev. 2002(2):CD001005. 
Appendix 1

\section{Questionnaire}

English condensed version of "Questions about your asthma". Answers were mostly multiple choice but sometimes open answers were required. Typical choices were "Yes", "No" and "Don't know," if not otherwise specified. Abbreviations used: Inhaled corticosteroids (ICS), short- and long acting beta-2-agonist (SABA) and (LABA).

\section{Background data}

1. What is your age and gender? years Female/Male

2. How many years have you had asthma? $<1$ year, 1-5 years, $>5$ years

3. What is your main occupation? - full-, part-time or domestic worker, unemployed, student or other specified alternative?

4. Do your smoke daily?

\section{Symptoms}

5. Do you get asthma/ rhinitis symptoms from pollen (birch, grass or mugwort) or to furred animals (cat, dog or horse)?

6. Have you woken up due to cough, wheeze or shortness of breath in the last week?

7. Have your made emergency/unscheduled urgent care visits to hospital, primary care or paediatric care due to asthma in the last six months? If yes: once, twice, > two times.

8. Have you been hospitalised due to asthma in the last six months?

9. Have been home from work or studies due to asthma in the last six months? If yes: once, twice, > two times. If yes, nr. of days?

Medication - answers if not otherwise specified - regularly, periodically or not at all.

10. Have you used SABA due to asthma symptoms more than twice in the last week?

11. Have you used ICS the last six months?

12. Have you used LABA the last six months?

13. Have you used leukotrien antagonist the last six months?

14. Have you used systemic corticosteroids due to asthma exacerbation the last six months? If yes, specify how many times.

15. Have your used homeopathic drugs, zone therapy or acupuncture the last six months?

16. Have you renounced to pick up your prescribed asthma medication due to costs in the last year?

\section{Medical care}

17. Do you go to annual follow-ups for your asthma?

18. Do you know which doctor is responsible for your asthma treatment?

19. Do you use a peak flow meter? often, sometimes, seldom or never

20. Have you ever received instructions on how to inhale your medication?

Knowledge - answers "Yes absolutely", "Yes partially" and "No".

21. Do your know how to change your medicating at: infections, more asthma symptoms, deteriorated peak flow value?

22. Do your consider yourself to have sufficient knowledge of your asthma disease? 